ARTICLE

DOI: $10.1038 / \mathrm{s} 41467-018-05305-2$

\title{
Drug capture materials based on genomic DNA- functionalized magnetic nanoparticles
}

\author{
Carl M. Blumenfeld', Michael D. Schulz', Mariam S. Aboian², Mark W. Wilson², Terilynn Moore ${ }^{2}$,
} Steven W. Hetts ${ }^{2} \&$ Robert H. Grubbs ${ }^{1}$

Chemotherapy agents are notorious for producing severe side-effects. One approach to mitigating this off-target damage is to deliver the chemotherapy directly to a tumor via transarterial infusion, or similar procedures, and then sequestering any chemotherapeutic in the veins draining the target organ before it enters the systemic circulation. Materials capable of such drug capture are yet to be fully realized. Here, we report the covalent attachment of genomic DNA to iron-oxide nanoparticles. With these magnetic materials, we captured three common chemotherapy agents-doxorubicin, cisplatin, and epirubicin-from biological solutions. We achieved $98 \%$ capture of doxorubicin from human serum in $10 \mathrm{~min}$. We further demonstrate that DNA-coated particles can rescue cultured cardiac myoblasts from lethal levels of doxorubicin. Finally, the in vivo efficacy of these materials was demonstrated in a porcine model. The efficacy of these materials demonstrates the viability of genomic DNAcoated materials as substrates for drug capture applications.

\footnotetext{
${ }^{1}$ Arnold and Mabel Beckman Laboratories for Chemical Synthesis, Division of Chemistry and Chemical Engineering, California Institute of Technology, Pasadena, CA 91125, USA. ${ }^{2}$ Interventional Radiology Research Laboratory, Department of Radiology and Biomedical Imaging, University of California-San Francisco, San Francisco, CA 94143, USA. These authors contributed equally: Carl M. Blumenfeld, Michael D. Schulz. Correspondence and requests for materials should be addressed to R.H.G. (email: rhg@caltech.edu)
} 
T he systemic toxicity of chemotherapy is a widely recognized problem in oncology. Off-target damage often persists indefinitely, adversely affects patient survival, and restricts dose and treatment options ${ }^{1,2}$. Direct administration of chemotherapy agents to the tumor via transarterial chemoembolization (TACE), or similar procedures, followed by sequestration of any chemotherapeutic that enters systemic circulation would mitigate this damage if materials capable of such drug capture were fully realized ${ }^{3,4}$.

Hepatocellular carcinoma (HCC) is the third leading cause of cancer-related deaths worldwide ${ }^{5}$. Liver transplantation is the most definitive approach for treatment; however, less than $30 \%$ of HCC patients are eligible ${ }^{6}$. Direct delivery of drug to a tumor via intraarterial chemotherapy (IAC) and its variant, TACE, is often used as a bridge to transplantation, shrinking HCC or at least controlling its growth through recurrent treatments until curative transplant is possible. In cases where surgery is untenable, chemotherapy is often the only recourse. Targeted therapy, however, does not completely eliminate side-effects.

Three of the most common drugs used to treat HCC are doxorubicin (DOX), epirubicin (EPI), and cisplatin (Fig. 1c), all of which act on DNA ${ }^{7}$. DOX and EPI function by intercalating between DNA base pairs, while cisplatin is a DNA crosslinker that functions by binding to guanine $e^{8,9}$. A major problem for these anticancer compounds is toxicity in non-targeted tissues. DOX and EPI toxicity can result in cardiomyopathy and congestive heart failure ${ }^{8-10}$. Similarly, cisplatin elicits side-effects including extensive nephrotoxicity and neurotoxicity ${ }^{11,12}$. To reduce the likelihood of cardiac toxicity, cumulative dosage of DOX is generally limited by clinicians to $400-450 \mathrm{mg} / \mathrm{m}^{2}$, though lower cumulative dosages $\left(300 \mathrm{mg} / \mathrm{m}^{2}\right)$ are known to increase the risk of congestive heart failure ${ }^{13,14}$. Still, a single standard dose of DOX $(50-75 \mathrm{mg})$ can result in severe side-effects, yet higher dosages of DOX are known to be associated with greater tumor suppression. Consequently, a balance must be struck in order to maximize drug dose, leading to better tumor suppression, while simultaneously avoiding catastrophic off-target toxicity. Although limiting a patient's lifetime cumulative dose is the most effective way to avoid cardiotoxicity, this approach necessarily limits anticancer efficacy ${ }^{15}$.

The unwanted systemic toxicity of chemotherapy agents has inspired a number of more targeted approaches. One such approach is TACE, during which liver blood flow is occluded in conjunction with administration of high dose chemotherapy directly to the tumor ${ }^{3,16}$. Both during TACE and after liver blood flow is restored, however, up to $50 \%$ of residual chemotherapeutics enter systemic circulation and cause off-target toxicity ${ }^{17}$

Efforts have been made toward reducing non-targeted toxicity during TACE. In 2014 Patel and coworkers proposed chemotherapy filtration devices ("ChemoFilters") that employed sulfonated ion-exchange resins with affinity for DOX. Such a device could be deployed via catheter in the hepatic vein, "downstream" from the site of chemotherapy administration, where it can intercept any residual chemotherapy agents before they reach the heart and enter systemic circulation. They demonstrated a $52 \%$ reduction in DOX concentration from porcine serum over $10 \mathrm{~min}$, and showed that such a device could be successfully deployed during a simulated TACE procedure ${ }^{3}$. In 2016, the ChemoFilter approach inspired the development of more elaborate block copolymer membranes for DOX capture, which achieved up to $90 \%$ removal of DOX in $31 \mathrm{~min}$ from phosphate buffered saline (PBS) 4 .

A ChemoFilter device is intended to be placed downstream of blood outflow from the tumor that is being treated with intraarterial chemotherapeutics. In the case of HCC, which is located in the liver, the ChemoFilter would be placed into the suprahepatic inferior vena cava (IVC) immediately prior to administration of IAC into the hepatic artery and then removed shortly after
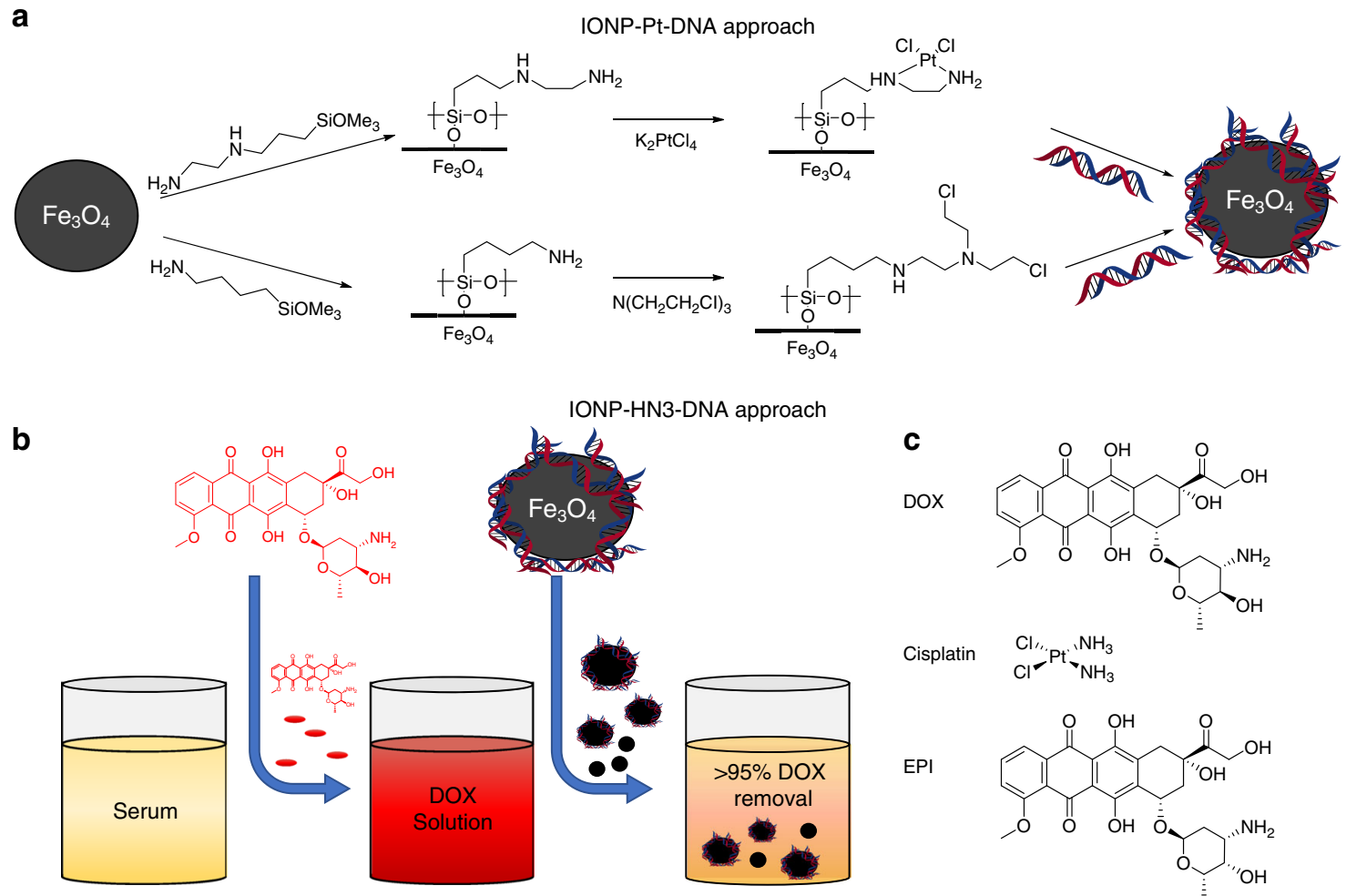

Fig. 1 Experimental approach. a Two synthetic approaches for covalently attaching genomic DNA onto iron-oxide nanoparticle (IONP) surfaces. b Drug capture concept. c Three common chemotherapy agents used in this study 
drug capture has been achieved ${ }^{3,18}$. Here we report the development of a drug-capture material based on genomic DNA and iron oxide particles. In vitro studies confirm that these materials can rescue cells from the toxic effects of DOX. A ChemoFilter device is constructed from this material that rapidly removes chemotherapy agents from relevant biological solutions, including human serum and porcine blood, and in vivo studies confirm that DOX can be removed from the bloodstream by an intraarterial device constructed from these iron oxide/genomic DNA materials.

\section{Results and discussion}

Material design and synthesis. Inspired by the ChemoFilter concept, we designed and synthesized DNA-functionalized materials based on magnetite $\left(\mathrm{Fe}_{3} \mathrm{O}_{4}\right)$ nanoparticles, capable of rapidly capturing chemotherapy agents. Central to our approach is the direct covalent attachment of genomic DNA. Functionalizing surfaces with DNA has historically involved tagging either the backbone or bases of synthetic DNA with an appropriate moiety, or attaching the DNA via a reactive end-group. These approaches are highly useful and enable complete control of the DNA sequence used resulting in the development of numerous interesting materials ${ }^{19-26}$; however, they are limited by the relatively high cost of synthetic DNA. The synthesis of large amounts of such materials would be prohibitively expensive for most applications.

Functionalization with genomic DNA is an alternative approach that may be appropriate for certain applications; however, this approach is relatively unexplored. Pierre and coworkers recently synthesized magnetic nanoparticles with surface-bound intercalating groups, and showed that such materials can bind to genomic $\mathrm{DNA}^{27}$. To our knowledge, however, no one has reported the covalent attachment of genomic DNA to a surface. Here, we report two methods of attaching genomic DNA to nanoparticles, both on multi-gram scale (Fig. 1a). We show that the resulting materials are capable of removing DNA-targeting chemotherapy agents from solution both rapidly and in the presence of potential biological intereferents (e.g., serum proteins and other blood components).

DNA-alkylating agents are a common motif in chemotherapy. By forming covalent crosslinks between DNA strands, these drugs prevent the DNA from being accurately duplicated, ultimately leading to apoptosis. To attach genomic DNA to magnetic nanoparticles, we used an approach analogous to DNA-alkylating/crosslinking drugs (Fig. 1a). The first approach was inspired by cisplatin. To synthesize IONP-Pt-DNA samples, the

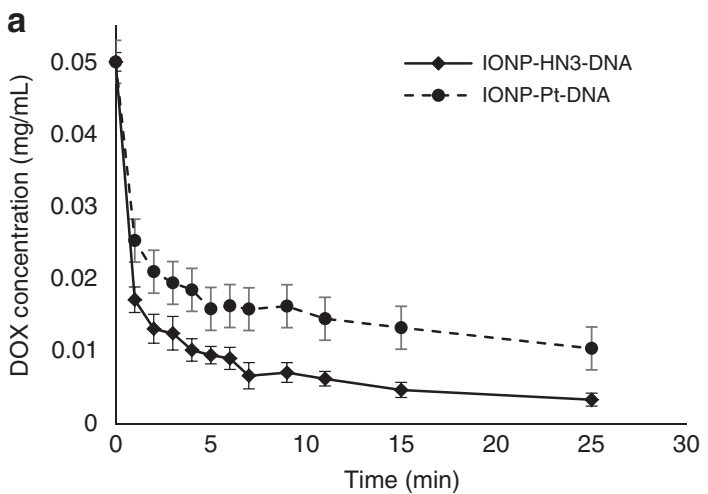

hydroxylated surface of $\mathrm{Fe}_{3} \mathrm{O}_{4}$ was silylated with $\mathrm{N}$-(2-aminoethyl)-3-aminopropyltrimethoxysilane exposing a chelating diamine functionality. This sample was treated with an excess of potassium tetrachloroplatinate to create an analog of cisplatin by which DNA could be anchored to the surface. Cisplatin's cytotoxicity is thought to stem from its coordination with nucleophilic N7-sites of purine bases, resulting in crosslinks ${ }^{28}$. We hoped to accomplish DNA crosslinking to the surface through this mechanism. The sample was then exposed to DNA to produce IONP-Pt-DNA.

The second approach was modeled on nitrogen mustard chemotherapy agents. IONP-HN3-DNA samples were prepared first by functionalizing $\mathrm{Fe}_{3} \mathrm{O}_{4}$ with 4 -aminobutyltriethoxysilane to install free amines on the surface. This particle was then treated with excess tris (2-chloroethyl)amine hydrochloride $(\mathrm{HN} 3 \cdot \mathrm{HCl})$ to create a scaffold for DNA functionalization. $\mathrm{HN} 3 \cdot \mathrm{HCl}$, the hydrochloride salt of the nitrogen mustard $\mathrm{HN} 3$, undergoes aziridinium formation when deprotonated, and is attacked readily by the nucleophilic moieties of $\mathrm{DNA}^{29}$. The functionalized particle was exposed to DNA resulting in IONP-HN3-DNA. Both materials were characterized by scanning electron microscopy, electron dispersive scattering (EDS), elemental analysis, and infrared spectroscopy (see Supplementary Figs. 2\& 3 and 11-24, and Supplementary Table 1). Microscopy images of the particles in solution revealed significant aggregation resulting in an average particle diameter of $4.2 \mu \mathrm{m}$ with several larger $(>10 \mu \mathrm{m})$ aggregates. Elemental analysis indicated that these aggregates were $18 \%$ DNA by mass in the case of IONP-HN3-DNA and $14.7 \%$ DNA by mass in the case of IONP-Pt-DNA.

In vitro testing in simple solutions, serum, and blood. In order to evaluate the efficacy of our materials at scavenging chemotherapy agents from solution we studied DOX-binding in PBS and human serum at $37^{\circ} \mathrm{C}$ to approximate the biological environment in which these materials would have to operate (Fig. 1b). We found that IONP-HN3-DNA was able to capture $93 \%$ of DOX, on average, from a $0.05 \mathrm{mg} / \mathrm{mL}$ solution of human serum in $25 \mathrm{~min}$, while IONP-Pt-DNA averaged 79\% (Fig. 2a). In both cases, the kinetics were extremely rapid, with about $50 \%$ of DOX capture occurring within $1 \mathrm{~min}$ in the case of IONP-Pt-DNA and over $65 \%$ DOX capture occurring within 1 min for IONP-HN3DNA. Based on these results, we carried out all further tests with IONP-HN3-DNA.

Interestingly, both materials were highly effective, despite the known binding of DOX with serum albumin. It is known that DNA intercalation is the kinetically more favorable process ${ }^{30,31}$,

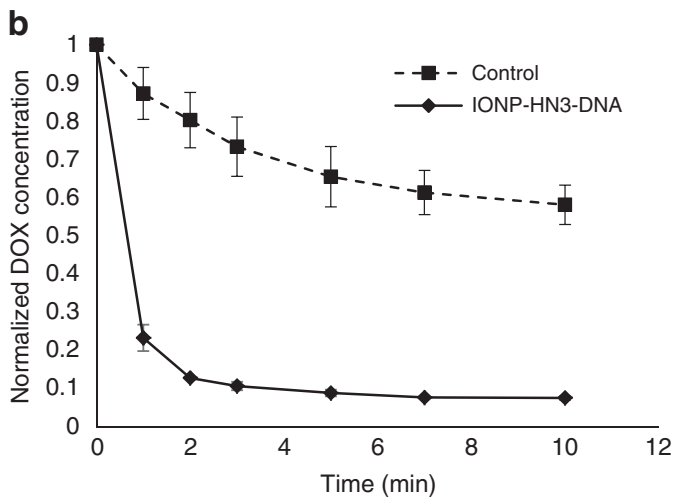

Fig. 2 DOX capture in human serum and porcine blood. a Decrease in DOX concentration in human serum, determined by fluorescence, as a result of DOX capture by IONP-HN3-DNA and IONP-Pt-DNA; $100 \pm 5 \mathrm{mg}$ particle in $20 \mathrm{~mL}(0.05 \mathrm{mg} / \mathrm{mL}), 1 \mathrm{mg}$ total DOX, $37^{\circ} \mathrm{C} ;$ error bars $=1 \mathrm{standard}$ deviation $(n=$ 3). $\mathbf{b}$ Decrease in DOX plasma concentration as a result of DOX capture by IONP-HN3-DNA from porcine whole blood; $100 \pm 5$ mg IONP-HN3-DNA in $20 \mathrm{~mL}(0.05 \mathrm{mg} / \mathrm{mL}), 1 \mathrm{mg}$ total $\mathrm{DOX}, 37^{\circ} \mathrm{C}$; error bars $=1$ standard deviation $(n=3)$ 
and we believe that this kinetic advantage enabled our material to capture DOX from serum solution, despite the thermodynamics being in favor of serum binding overall. We posit that over longer timescales, serum binding would be the dominant process; however, since TACE is a relatively short procedure $(<1 \mathrm{~h})$, we believe that kinetic factors will dominate in the performance of any material or device.

Drug capture was also evaluated in porcine whole blood, by measuring DOX plasma concentration over time. We observed some DOX removal due to binding to the non-plasma blood components, which we cannot deconvolute from capture by our materials. Nevertheless, there is rapid reduction of DOX concentration in the blood plasma within $1 \mathrm{~min}$ after exposure to our material, reaching a $92 \%$ reduction in DOX plasma concentration over $10 \mathrm{~min}$, in stark contrast to the control experiment (Fig. 2b). This experiment conclusively demonstrates that our materials are capable of capturing DOX from whole blood.

To better understand the DOX-capture capacity of IONPHN3-DNA, we performed a series of experiments in which nanoparticle loading was systematically varied (Fig. 3a, b, further data in the Supplementary Information). These experiments revealed a roughly linear trend in DOX-capture as a function of the amount of particle added, up to a plateau around $100 \mathrm{mg}$

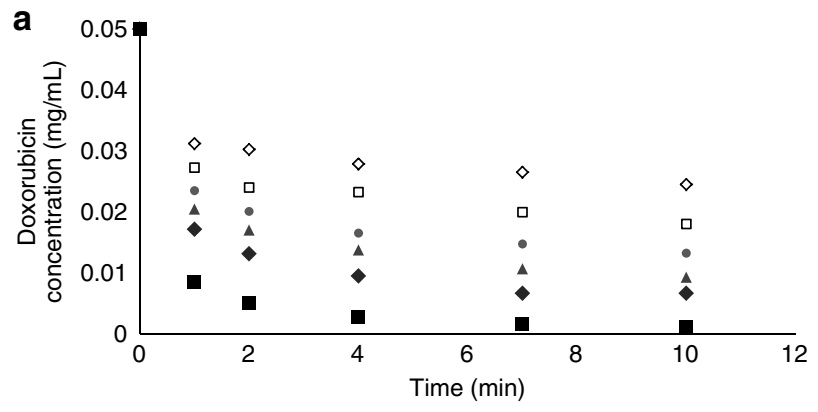

$\diamond 10 \mathrm{mg}$ 口 $20 \mathrm{mg} \bullet 30 \mathrm{mg} \Delta 40 \mathrm{mg} \bullet 50 \mathrm{mg}$ - $100 \mathrm{mg}$ IONP-HN3-DNA
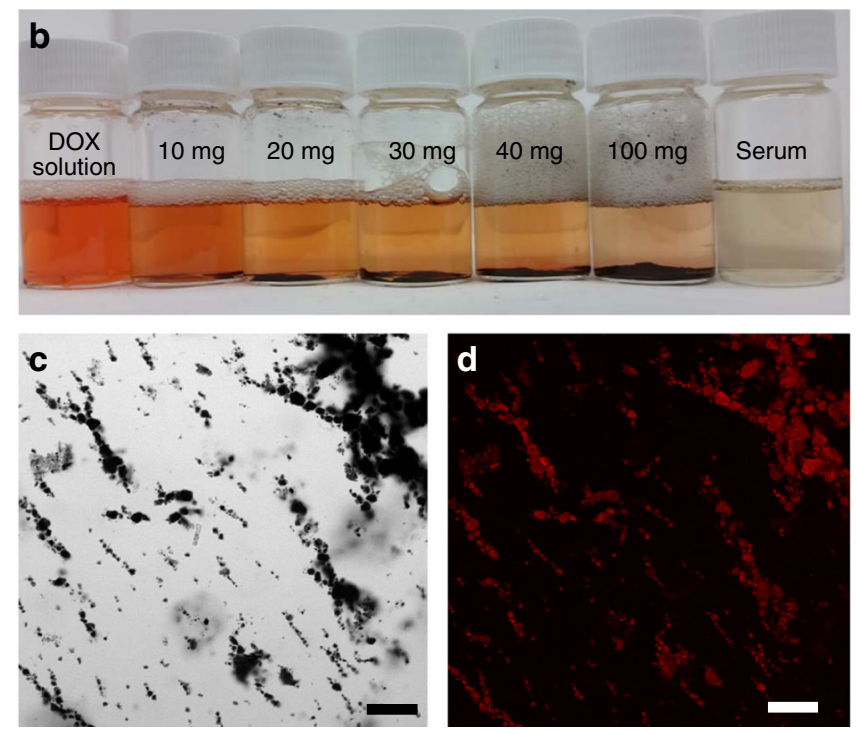

Fig. 3 DOX capture with IONP-HN3-DNA particles. a DOX capture as a function of the amount of IONP-HN3-DNA from a DOX serum solution $(0.5 \mathrm{mg}$ total DOX, $0.05 \mathrm{mg} / \mathrm{mL}$ ); average of three experiments, data set with error bars in Supplementary Fig. 6. b Resulting serum solutions from experiments summarized in a. c Brightfield image of IONP-HN3-DNA aggregates bound to DOX; scale bar $=50 \mu \mathrm{m}$. d Fluorescence from DOX bound to IONP-HN3-DNA; scale bar $=50 \mu \mathrm{m}$ material added per mg DOX, resulting in $\sim 90 \%$ DOX capture in 10 min. Further DOX capture appears less favorable after this point. We believe this plateau is the result of competition with serum binding, which makes that portion of DOX unavailable for capture by our particles, as well as the typical kinetic effects of diminishing concentration. The absorption of DOX onto the particles was further verified by performing confocal fluorescence microscopy (Fig. 3c and d). This technique allowed visualization of the fluorescence of DOX bound to the surface of the particles.

Our approach is general for all DNA-targeting chemotherapy agents. To demonstrate this fact, we performed further experiments on two additional common DNA-targeting chemotherapeutics, cisplatin and EPI. We performed an initial cisplatinbinding experiment in PBS solution with IONP-HN3-DNA and monitored the decrease of cisplatin concentration by inductively coupled plasma-mass spectrometry (ICP-MS). Approximately $20 \%$ of the cisplatin was captured from solution over $30 \mathrm{~min}$, with little improvement over longer time periods (see Supplementary Fig. 4). We confirmed the presence of captured cisplatin on the surface of the particles by $\mathrm{x}$-ray photoelectron spectroscopy. We believe these relatively low levels of drug capture are due to cisplatin not being in the aquo state, which happens intracellularly and is necessary in order to bind to DNA. Because the particles were not highly effective for cisplatin capture in PBS, we did not perform further experiments in more complex media such as serum or blood.

Along with DOX and cisplatin, EPI is among the most commonly used chemotherapeutic agents for treating HCC. We evaluated the efficacy of our materials for capturing EPI using a set of experiments analogous to those we used with DOX (see Supplementary Fig. 5). Our particles were highly effective at sequestering EPI from serum, with $68 \%$ captured after $25 \mathrm{~min}$. The sequestered amount would lead to a reduction in unwanted side-effects if achieved in vivo.

In vitro evaluation of biological efficacy. The ability of IONPHN3-DNA to detoxify DOX was tested in vitro in an H9C2 rat heart myoblast cell culture assay (Fig. 4). These experiments demonstrated that DNA-coated particles could rescue cultured cardiac myoblasts from lethal levels of DOX more effectively than the ion exchange resin Dowex, which itself had been previously shown to reduce levels of DOX in vivo ${ }^{3}$.

In vivo evaluation of drug capture. A device (Fig. 5a) consisting of IONP-HN3-DNA magnetically adhered to the surface of cylindrical rare-earth magnets strung along a PTFE-coated nitinol wire was evaluated using a closed loop flow model ${ }^{3}$ (see Supplementary Fig. 25) and subsequently tested in vivo using a porcine model. The device was inserted into the IVC and DOX was injected over $10 \mathrm{~min}$ at a rate of $2.5 \mathrm{~mL} / \mathrm{min}$ into the left common iliac vein proximal to the device (Fig. 5b). As the drug flowed through the IVC, it made contact with the IONP-HN3DNA adherent to the surface of the device and was captured. Blood aliquots were taken proximal to (upstream), adjacent to the midpoint of, and distal to (downstream from) the device using separate catheters. Peak DOX concentration was observed at $3 \mathrm{~min}$, since the blood at the injection site had recirculated and live injection was still underway. At 3 min (peak concentration), a $60 \%$ reduction in serum DOX concentration was observed half-way across the device, while a total reduction of $82 \%$ was observed at the end of the device (Fig. 5c, d).

In conclusion, we have demonstrated two viable synthetic pathways to genomic DNA-functionalized magnetic particles, both on multi-gram scale. Moreover, these methodologies for 

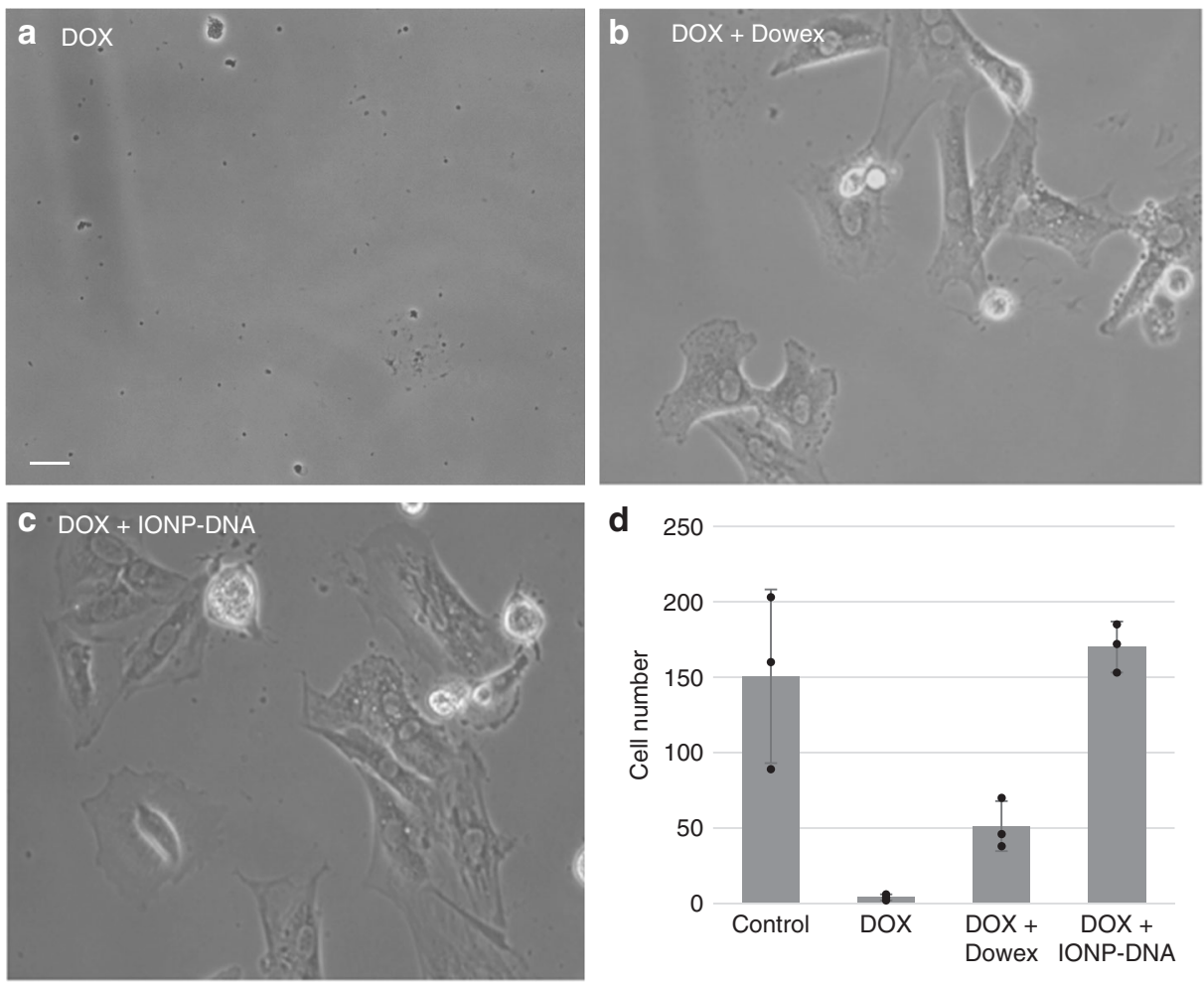

Fig. 4 IONP-HN3-DNA rescue cultured cells from DOX toxicity (scale bar $=5 \mu \mathrm{m}$ ). a Rat heart myoblasts $\mathrm{H} 9 \mathrm{C} 2 \mathrm{cultured}$ with $\mathrm{DOX}(0.05 \mathrm{mg} / \mathrm{mL})-$ myoblasts are killed by adding DOX to culture (DOX, d). b Myoblasts treated with DOX $(0.05 \mathrm{mg} / \mathrm{mL})$ and $0.19 \mathrm{~g}$ Dowex ion-exchange resin beadsmyoblasts are partially rescued ((DOX + Dowex, d). c Myoblasts treated with DOX $(0.05 \mathrm{mg} / \mathrm{mL})$ and $0.19 \mathrm{~g}$ IONP-HN3-DNA-myoblasts are completely rescued (DOX + IONP-DNA, d). d Cell counts for each experimental condition; error bars $=1$ standard deviation $(n=3)$
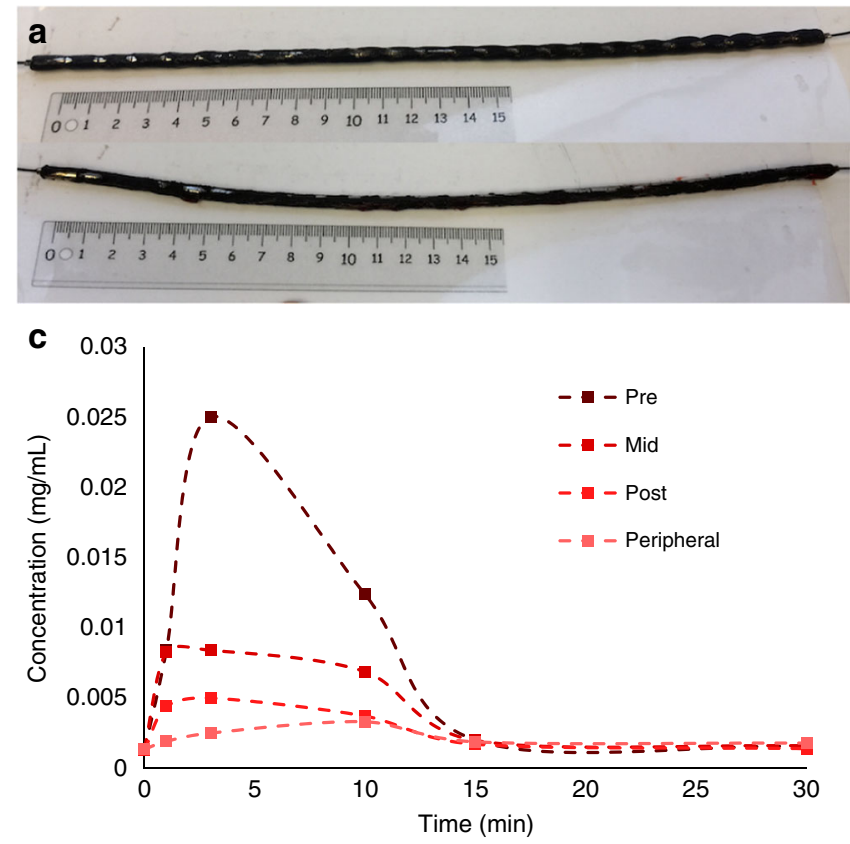
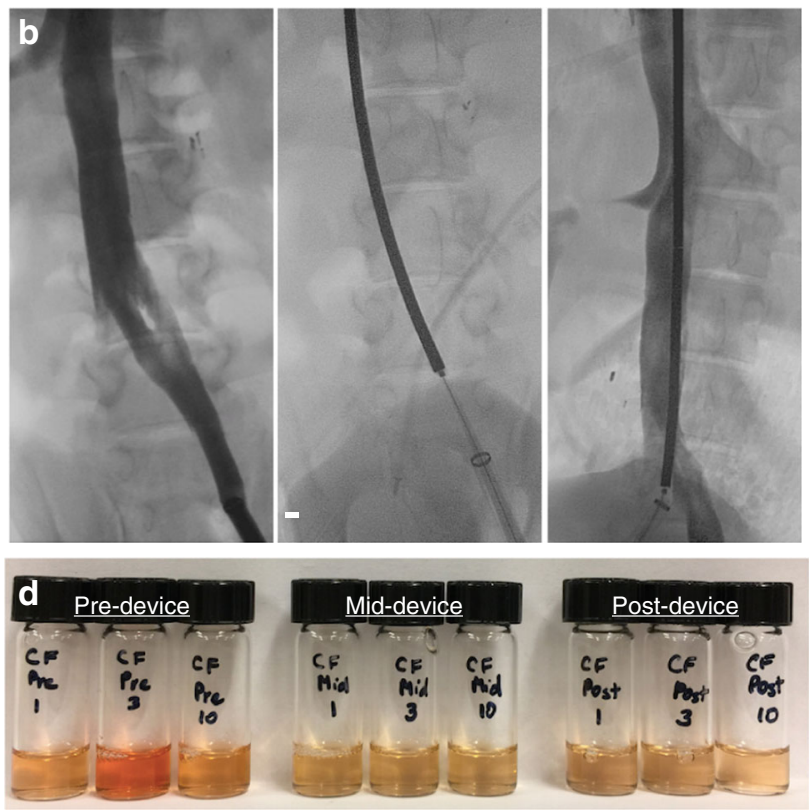

Post-device

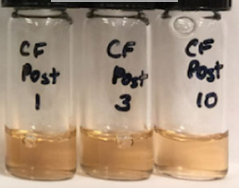

Fig. 5 In vivo results. a Device containing 25 magnets $(1 \mathrm{~cm} \times 0.5 \mathrm{~cm})$ with IONP-HN3-DNA coating (above), and the same device after the in vivo experiment (below), demonstrating minimal loss of particles after removal of the device. $\mathbf{b}$ Fluoroscopy images during in vivo porcine experiment demonstrating the inferior vena cava with opacified right renal veins (scale bar $=5 \mathrm{~mm}$ ). The device was placed within the inferior vena cava. The sampling catheters were placed immediately proximal to the device, prior to the renal vein, and distal to the device. c DOX concentration measurements from predevice, mid-device, post-device, and peripheral locations. $\mathbf{d}$ Plasma solutions from the experiment described in c: Left 3, pre-filter samples taken at 1, 3, and 10 min; Center 3, mid-filter samples taken at 1, 3, and 10 min; Right 3, post-filter samples taken at 1, 3, and 10 min 
DNA surface functionalization are not limited to magnetic metal oxides, but may also be exploited for other substrates. The synthesized materials captured three commonly used chemotherapy agents from relevant biological solutions (PBS, human serum, or porcine whole blood), at therapeutically relevant concentrations and timescales. A proof of concept device was developed, which demonstrated efficient capture of DOX in vivo. Similar devices could be readily developed that would potentially reduce the off-target toxicity and damaging side-effects associated with the use of DOX, cisplatin, and EPI during TACE or similar procedures. Ultimately, we believe our approach is general for all DNA-targeting chemotherapy drugs, and while further development is needed, we hope that this work will provide a foundation for future work on DNA-based materials and drug capture approaches both for oncologic and non-oncologic applications.

\section{Methods}

Instrumentation. Fluorescence measurements were made using a 96-well plate on a Molecular Devices FlexStation 3 Multi-mode microplate reader. Scanning electron micrographs (SEM), as well as EDS measurements were made on a Zeiss 1550VP field emission SEM equipped with an Oxford EDS module. ICP-MS was carried out on an HP 4500 ICP-MS equipped with a Cetac ASX-500 autosampler. Infrared measurements were made on a Nicolet iS50 Fourier transform infrared spectrometer equipped with a DuraScope ATR unit. C, H, N analyses were carried out using a PerkinElmer 2400 Series II CHN Elemental Analyzer. Fluorescence microscopy was performed on an inverted laser scanning confocal Zeiss LSM 710 microscope equipped with an argon laser and photomultiplier tube detector, and particle size was determined by image analysis of at least 100 particles measured on their widest dimension.

General procedures. Unless otherwise stated reactions were carried out on the bench. $\mathrm{Fe}_{3} \mathrm{O}_{4}$ (40 nm APS, 99\%) was purchased from Nanostructured \& Amorphous Materials, Inc. Silane reagents were purchased from Gelest, Inc. Genomic DNA (isolated from Herring sperm), human serum (OptiClear), H9C2 rat heart myoblasts, and cisplatin were purchased from Sigma Aldrich. DOX was purchased from LC Labs and EPI was purchased from Biotang Inc. Potassium tetrachloroplatinate was purchased from Pressure Chemicals. All reagents not otherwise mentioned were purchased from Sigma Aldrich, and were used without further purification.

Device construction. Twenty-five cylindrical rare-earth magnets (N52 grade, $5 \mathrm{~mm} \mathrm{OD} \times 1 \mathrm{~mm} \mathrm{ID} \times 5 \mathrm{~mm} \mathrm{~L}$, magnetized through the diameter) were strung along the length of a PTFE-coated nitinol wire (Terumo Glidewire). IONP-HN3DNA ( $1.0 \mathrm{~g})$ was suspended in water and subsequently magnetically adhered to the surface of this device.

Flow model experiments. A closed-circuit flow model was used to measure DOX clearance in a setting that simulates suprahepatic IVC conditions ${ }^{3,32}$. In this model, the porcine blood is circulated through the polyvinyl chloride tubing at a rate of $\sim 150 \mathrm{~mL} / \mathrm{min}$. The tubing size matches the average human hepatic vein measuring $1.2 \mathrm{~cm}$ as described previously ${ }^{18}$. Testing was performed with $200 \mathrm{~mL}$ porcine blood and samples were obtained from the tubing downstream from the device.

In vitro experiments. $\mathrm{H} 9 \mathrm{C} 2$ rat heart myoblasts (procured from Sigma Aldrich) were cultured in well plates (four replicates per condition) for $48 \mathrm{~h}$ after which cells were imaged with a light microscope and counted. In the control experiment, cells were cultured in RPMI medium with $10 \%$ fetal bovine serum. In the DOX experiment, cells were cultured with $0.05 \mathrm{mg} / \mathrm{mL}$ DOX added to the medium. In the cell rescue experiments, $0.19 \mathrm{~g}$ of either Dowex ion-exchange resin or IONP HN3-DNA was added to the culture media prior to introduction of DOX (final DOX concentration: $0.05 \mathrm{mg} / \mathrm{mL}$ )

In vivo porcine experiments. In vivo device testing was performed in farm swine $(n=1,45-50 \mathrm{~kg})$, which was under humane care. Experimentation was under compliance with UCSF IACUC protocols. The animal was monitored with blood pressure, pulse oximetry, heart rate, and electrocardiogram while under general anesthesia with isoflurane. Using fluoroscopic guidance, an $18 \mathrm{Fr}$ sheath was placed into the left external iliac vein for introduction of the device. A pre-device sampling catheter was introduced through the right external iliac vein with the tip terminating in the left common iliac vein near the bifurcation. An additional catheter was introduced via the right internal jugular vein with the tip distal to the device in the IVC (post-device). The mid-device catheter and peripheral catheters were introduced through the left internal jugular vein. Prior to the start of the experiments, patency of the venous system was demonstrated using contrast injection (Omnipaque). DOX was injected over $10 \mathrm{~min}$ at a rate of $2.5 \mathrm{~mL} / \mathrm{min}$ into the left common iliac vein proximal to the magnetic device. The pre-device DOX concentration was measured by sampling with a $5 \mathrm{Fr}$ catheter downstream of the DOX infusion. Blood aliquots were taken proximal to, adjacent to the midpoint of, and distal to the device using separate catheters. To clear the sampling catheters, $2 \mathrm{~mL}$ of blood was drawn immediately prior to taking the aliquot $(3 \mathrm{~mL})$. The blood samples were placed on ice until they were centrifuged to isolate the plasma fraction for analysis. A control experiment was also performed using the same procedures but with no device inserted.

Particle synthesis. IONP-Pt: $3.31 \mathrm{~g} \mathrm{Fe}_{3} \mathrm{O}_{4}$ was dried in vacuo at $120^{\circ} \mathrm{C}$. Upon cooling, the sealed material was introduced into an inert atmosphere nitrogen glovebox. To the $\mathrm{Fe}_{3} \mathrm{O}_{4}$ was added $23 \mathrm{~mL}$ anhydrous toluene along with $4 \mathrm{~mL} \mathrm{~N}$ (2-aminoethyl)-3-aminopropyltrimethoxysilane. The reaction was mechanically stirred on the bench at $110^{\circ} \mathrm{C}$ for $2 \mathrm{~h}$ and subsequently dried in vacuo at $110^{\circ} \mathrm{C}$ for $20 \mathrm{~h}$. The reaction mixture along with $1.0 \mathrm{~g} \mathrm{~K}_{2} \mathrm{PtCl}_{4}$, was stirred at $70{ }^{\circ} \mathrm{C}$ for $21 \mathrm{~min}$ and then washed three times with water. Following this, the mixture was diluted to a total volume of $450 \mathrm{~mL}$ with $18.2 \mathrm{M} \Omega$ water was treated with $1.3 \mathrm{~g} \mathrm{KCl}$ and an additional $10 \mathrm{~mL}$ water.

IONP-Pt-DNA: IONP-Pt materials along with $5.1 \mathrm{~g}$ deoxyribonucleic acid from herring sperm were mechanically stirred in $450 \mathrm{~mL} 18.2 \mathrm{M} \Omega$ water at $37^{\circ} \mathrm{C}$ for $20 \mathrm{~h}$. To ensure covalent attachment as opposed to being physically adsorbed, the particles were isolated from the reaction mixture, washed three times under vigorous mechanical stirring with $18.2 \mathrm{M} \Omega$ water $(400 \mathrm{~mL})$ in order to remove unbound DNA, frozen, and lyophilized to afford $3.08 \mathrm{~g}$ IONP-Pt-DNA (79\% yield based on elemental analysis of DNA content).

IONP-NH2: $4.2 \mathrm{~g}$ Of $\mathrm{Fe}_{3} \mathrm{O}_{4}$ was dried in vacuo at $120^{\circ} \mathrm{C}$. The $\mathrm{Fe}_{3} \mathrm{O}_{4}$ was allowed to cool to room temperature under vacuum. To the $\mathrm{Fe}_{3} \mathrm{O}_{4}$ was added to $25 \mathrm{~mL}$ toluene (freshly dried over magnesium sulfate) and $3.2 \mathrm{~mL} \mathrm{4-}$ aminobutyltriethoxysilane. The reaction was sealed and stirred mechanically for $2 \mathrm{~h}$ at $120^{\circ} \mathrm{C}$. The reaction was removed from heat and the particles were isolated from the toluene solution. The reaction mixture was washed once with toluene and subsequently dried in vacuo at $120^{\circ} \mathrm{C}$ for $1 \mathrm{~h}$ and $45 \mathrm{~min} .4 .02 \mathrm{~g}$ of IONP-HN3 was isolated.

IONP-HN3-DNA: $3.4750 \mathrm{~g}$ IONP-HN3 was added to a vial along with $1.02 \mathrm{~g}$ $\mathrm{HN} 3 \cdot \mathrm{HCl}$ and dimethylformamide $(30 \mathrm{~mL})$. The reaction was stirred mechanically for $1 \mathrm{~h}$ at room temperature at which point, the particles were isolated from the dimethylformamide. The particles were then washed three times with dimethylformamide. The isolated particle as well as $3.35 \mathrm{~g}$ deoxyribonucleic acid from herring sperm were transferred into a flask along with $400 \mathrm{~mL} 18.2 \mathrm{M} \Omega$ water. The reaction was mechanically stirred at $38^{\circ} \mathrm{C}$ for $17 \mathrm{~h}$ and $45 \mathrm{~min}$. To ensure covalent attachment and to remove any unbound DNA, the particles were then washed thoroughly under vigorous mechanical stirring three times with $18.2 \mathrm{M} \Omega$ water $(400 \mathrm{~mL})$ and magnetic separation. The particles were then frozen in liquid nitrogen and lyophilized to afford $3.79 \mathrm{~g}$ of IONP-HN3-DNA (89\% yield as calculated above).

Representative binding studies. DOX: To a scintillation vial was added $19 \mathrm{~mL}$ human serum. Drug was injected at a concentration of $1 \mathrm{mg} / \mathrm{mL}$ from a concentrated stock, to bring the total concentration to $\sim 0.05 \mathrm{mg} / \mathrm{mL}$. An initial time point is taken before drug capture. DNA particles $(100 \pm 5 \mathrm{mg})$ were added to the serum mixture, which is constantly, mechanically stirred. $20 \mathrm{~s}$ before a time point is taken, a strong, rare earth, magnet is used to isolate the particles at which point a $100 \mu \mathrm{L}$ aliquot is taken and placed in a 96-well microplate. The solutions are then measured by way of fluorescence on a microplate reader.

Cisplatin: Phosphate-buffered saline solution $(19 \mathrm{~mL})$ was added to a scintillation vial. Cisplatin solution $(1 \mathrm{~mL}, 1 \mathrm{mg} / \mathrm{mL}$ solution) was then injected, followed by $117 \pm 5 \mathrm{mg}$ of IONP-HN3-DNA, and the mixture was mechanically stirred over the course of an hour. At predetermined time points the magnetic materials were temporarily isolated using an external magnet so that $100 \mu \mathrm{L}$ aliquots could be taken, which were diluted $200 \times$ in $2 \%$ nitric acid solution and subsequently analyzed by ICP-MS to determine the concentration of platinum remaining in solution.

EPI: Human serum $(19 \mathrm{~mL})$ was added to a scintillation vial. EPI solution in water $(1 \mathrm{~mL}, 1 \mathrm{mg} / \mathrm{mL}$ solution) was then added. The particles $(100 \pm 5 \mathrm{mg}$ IONP HN3-DNA) were then added and the solution was mechanically stirred over the course of $25 \mathrm{~min}$. At predetermined time points, the magnetic materials were temporarily isolated using an external magnet and $100 \mu \mathrm{L}$ aliquots were taken, which were subsequently diluted $100 \times$ in water and analyzed by fluorescence on a microplate reader in order to characterize the amount of EPI remaining in solution.

Data availability. All data supporting the findings of this study are available within the article and its Supplementary Information. All other data are available from the corresponding author upon reasonable request. 
Received: 12 May 2017 Accepted: 20 June 2018

Published online: 20 July 2018

\section{References}

1. Cleeland, C. S. et al. Reducing the toxicity of cancer therapy: recognizing needs, taking action. Nat. Rev. Clin. Oncol. 9, 1-8 (2012).

2. Tatonetti, N. P., Ye, P. P., Daneshjou, R. \& Altman, R. B. Data-driven prediction of drug effects and interactions. Sci. Transl. Med. 4, 125ra31 (2012).

3. Patel, A. S. et al. Development and validation of endovascular chemotherapy filter device for removing high-dose doxorubicin: preclinical study. J. Med. Device. 8, 0410081-0410088 (2014).

4. Chen, X. C. et al. Block copolymer membranes for efficient capture of a chemotherapy drug. ACS Macro Lett. 5, 936-941 (2016). https://doi.org/ 10.1021/acsmacrolett.6b00459

5. Altekruse, S. F., McGlynn, K. A. \& Reichman, M. E. Hepatocellular carcinoma incidence, mortality, and survival trends in the United States from 1975 to 2005. J. Clin. Oncol. 27, 1485-1491 (2009).

6. Belghiti, J. \& Kianmanesh, R. Surgical treatment of hepatocellular carcinoma. HPB (Oxford). 7, 42-49 (2005).

7. Marelli, L. et al. Transarterial therapy for hepatocellular carcinoma: Which technique is more effective? A systematic review of cohort and randomized studies. Cardiovasc. Interv. Radiol. 30, 6-25 (2007).

8. Cheung-Ong, K., Giaever, G. \& Nislow, C. DNA-damaging agents in cancer chemotherapy: serendipity and chemical biology. Chem. Biol. 20, 648-659 (2013).

9. Minotti, G., Menna, P., Salvatorelli, E., Cairo, G. \& Gianni, L. Anthracyclines: molecular advances and pharmacologic developments in antitumor activity and cardiotoxicity. Pharmacol. Rev. 56, 185-229 (2004).

10. Ryberg, M. et al. Epirubicin cardiotoxicity: an analysis of 469 patients with metastatic breast cancer. J. Clin. Oncol. 16, 3502-3508 (1998).

11. Miller, R. P., Tadagavadi, R. K., Ramesh, G. \& Reeves, W. B. Mechanisms of cisplatin nephrotoxicity. Toxins (Basel) 2, 2490-2518 (2010).

12. Wang, D. \& Lippard, S. J. Cellular processing of platinum anticancer drugs. Nat. Rev. Drug Deliv. 4, 307-320 (2005).

13. Rahman, A. M., Yusuf, S. W. \& Ewer, M. S. Anthracycline-induced cardiotoxicity and the cardiac-sparing effect of liposomal formulation. Int. J. Nanomed. 2, 567-583 (2007)

14. Buzdar, A. U., Marcus, C., Smith, T. L. \& Blumenschein, G. R. Early and delayed clinical cardiotoxicity of doxorubicin. Cancer 55, 2761-2765 (1985).

15. Yeh, E. T. H. \& Bickford, C. L. Cardiovascular complications of cancer therapy. J. Am. Coll. Cardiol. 53, 2231-2247 (2009).

16. Tsochatzis, E. A., Germani, G. \& Burroughs, A. K. Transarterial chemoembolization, transarterial chemotherapy, and intra-arterial chemotherapy for hepatocellular carcinoma treatment. Semin. Oncol. 37, 89-93 (2010)

17. Hwu, W. J. et al. A clinical-pharmacological evaluation of percutaneous isolated hepatic infusion of doxorubicin in patients with unresectable liver tumors. Oncol. Res. 11, 529-537 (1999).

18. Aboian, M. S. et al. In vitro clearance of doxorubicin with a DNA-based filtration device designed for intravascular use with intra-arterial chemotherapy. Biomed. Microdevices 18, 98 (2016).

19. Hurst, S. J. et al. Synthetically programmable DNA binding domains in aggregates of DNA-functionalized gold nanoparticles. Small 5, 2156-2161 (2009).

20. Cohen, G., Deutsch, J., Fineberg, J. \& Levine, A. Covalent attachment of hybridizable oligonucleotides to glass supports. Nucleic Acids Res. 25, 911-912 (1997).

21. Beier, M. \& Hoheisel, J. D. Versatile derivatisation of solid support media for covalent bonding on DNA-microchips. Nucleic Acids Res. 27, 1970-1977 (1999).

22. Kumar, A., Larsson, O., Parodi, D. \& Liang, Z. Silanized nucleic acids: a general platform for DNA immobilization. Nucleic Acids Res. 28, E71 (2000).

23. Yao, G. et al. Clicking DNA to gold nanoparticles: poly-adenine-mediated formation of monovalent DNA-gold nanoparticle conjugates with nearly quantitative yield. NPG Asia Mater. 7, e159 (2015).

24. Mirkin, C. A., Letsinger, R. L., Mucic, R. C. \& Storhoff, J. J. A DNA-based method for rationally assembling nanoparticles into macroscopic materials. Nature 382, 607-609 (1996).

25. Macfarlane, R. J. et al. Nanoparticle superlattice engineering with DNA Science 334, 204-208 (2011).

26. Lipshutz, R. J., Fodor, S. P., Gingeras, T. R. \& Lockhart, D. J. High density synthetic oligonucleotide arrays. Nat. Genet. 21, 20-24 (1999).

27. Smolensky, E. D., Peterson, K. L., Weitz, E. A., Lewandowski, C. \& Pierre, C. Magnetoluminescent light switches-dual modality in DNA detection eric. J. Am. Chem. Soc. 135, 8966-8972 (2013).
28. Siddik, Z. H. Cisplatin: mode of cytotoxic action and molecular basis of resistance. Oncogene 22, 7265-7279 (2003).

29. Polavarapu, A., Stillabower, J. A., Stubblefield, S. G. W., Taylor, W. M. \& Baik, $\mathrm{M}$. H. The mechanism of guanine alkylation by nitrogen mustards: a computational study. J. Org. Chem. 77, 5914-5921 (2012).

30. Agudelo, D. et al. Probing the binding sites of antibiotic drugs doxorubicin and $\mathrm{N}$-(trifluoroacetyl) doxorubicin with human and bovine serum albumins. PLoS ONE 7, 1-13 (2012).

31. Agudelo, D., Bourassa, P., Bérubé, G. \& Tajmir-Riahi, H. A. Intercalation of antitumor drug doxorubicin and its analogue by DNA duplex: structural features and biological implications. Int. J. Biol. Macromol. 66, 144-150 (2014).

32. Patel, A. et al. O-016 development and validation of an endovascular chemotherapy filter device for removing high-dose doxorubicin from the blood: <em>In Vivo</em> Porcine Study. J. Neurointerv. Surg. 6, A9 LP-A9 L9 (2014).

\section{Acknowledgements}

The authors gratefully acknowledge the financial support from the NIH (R01CA194533, Hetts; 5T32EB001631-13, Aboian). Confocal imaging was performed in the Biological Imaging Facility, with the support of the Caltech Beckman Institute and the Arnold and Mabel Beckman Foundation. The authors additionally acknowledge support from the Beckman Institute of the California Institute of Technology to the Molecular Materials Research Center. The authors wish to thank Dr. Andres Collazo for assistance with imaging, Mr. Daryl Yee for assistance with X-ray photoelectron spectroscopy, and Wesley Kuo for performing flow model experiments and for assisting with fluoroscopy image acquisition during in vivo porcine experiments. We would like to thank UCSF Interventional Radiology laboratory members for assisting with in vivo porcine experiments including Carol Stillson, Dr. Maythem Saeed, Anqi Liang, Joshua Fisher, Jay Yu, and Dr. Caroline Jordan. We would also like to thank Sravani Kondapavulur for expert advice on the assembly of the magnetic device.

\section{Author contributions}

C.M.B. and M.D.S. designed materials and devices, synthesized materials, and assisted with in vitro experiments. M.S.A performed cell culture experiments, and performed in vitro and in vivo experiments with the magnetic device. T.M., M.W.W., and S.W.H supervised and performed in vivo experiments. R.H.G. and S.W.H. supervised the project. All authors discussed the results.

\section{Additional information}

Supplementary Information accompanies this paper at https://doi.org/10.1038/s41467018-05305-2.

Competing interests: S.W.H. and M.W.W. have a royalty agreement through the University of California and currently licensed to Penumbra, Inc., should a medical device resulting from the underlying endovascular filtration technology be developed and marketed. A patent application (WO2018048829A1) has been filed by the California Institute of Technology that covers the materials described in this paper. The remaining authors declare no competing interests.

Reprints and permission information is available online at http://npg.nature.com/ reprintsandpermissions/

Publisher's note: Springer Nature remains neutral with regard to jurisdictional claims in published maps and institutional affiliations.

Open Access This article is licensed under a Creative Common Attribution 4.0 International License, which permits use, sharing, adaptation, distribution and reproduction in any medium or format, as long as you give appropriate credit to the original author(s) and the source, provide a link to the Creative Commons license, and indicate if changes were made. The images or other third party material in this article are included in the article's Creative Commons license, unless indicated otherwise in a credit line to the material. If material is not included in the article's Creative Commons license and your intended use is not permitted by statutory regulation or exceeds the permitted use, you will need to obtain permission directly from the copyright holder. To view a copy of this license, visit http://creativecommons.org/ licenses/by/4.0/

(C) The Author(s) 2018 